\title{
Correction to: Performance, biochemical and physiological parameters of Dorper $\times$ Santa Ines lambs fed with three levels of metabolizable energy
}

\section{Angélica Bonafede Martins Teixeira ${ }^{1}$ Bruno Raphael Fasolli Schuh ${ }^{1} \cdot$ Veridiana Lourenço Daley $^{2}$. Pedro Henrique Nicolau Pinto ${ }^{3}$. Sergio Rodrigo Fernandes ${ }^{4}$. José Antônio de Freitas ${ }^{1}$}

Published online: 27 July 2021

C) Springer Nature B.V. 2021

Correction to: Tropical Animal Health and Production (2021) 53:353

https://doi.org/10.1007/s11250-021-02797-x

The article was originally published with incorrect affiliation for author Veridiana Lourenço Daley. Affiliation 2 should read:

Department of Dairy Science, Virginia Tech, Blacksburg, VA, USA

The original article has been corrected.

Publisher's note Springer Nature remains neutral with regard to jurisdictional claims in published maps and institutional affiliations.

The original article can be found online at https://doi.org/10.1007/ s11250-021-02797-x

Sergio Rodrigo Fernandes srfernandes83@gmail.com

1 Department of Animal Science, Federal University of Paraná, Palotina Campus, Palotina, PR, Brazil

2 Department of Dairy Science, Virginia Tech, Blacksburg, VA, USA

3 Department of Reproduction, Fluminense Federal University, Niterói, RJ, Brazil

4 Department of Animal Science, State University of Londrina, Londrina, PR, Brazil 